\title{
Sentidos de vida e morte: reflexões de pacientes em cuidados paliativos
}

\author{
Leonardo Bohner Hoffmann* \\ Ana Beatriz Brandão Santos \\ Ricardo Tavares Carvalho \\ Universidade de São Paulo, Faculdade de Medicina, São Paulo, SP, Brasil
}

\begin{abstract}
Resumo: Cuidados paliativos visam amenizar o sofrimento de pacientes com doenças crônicas e ameaçadoras da vida nas dimensões: física, social, psicológica e espiritual. Na dimensão espiritual, procura-se imbuir de sentido aspectos transcendentais, como vida e morte. Conhecer esses sentidos é o objetivo deste estudo, que se trata de pesquisa qualitativa de caráter exploratório e faz uso de entrevistas semiestruturadas para a coleta de dados e análise do discurso. Foram entrevistados quatro pacientes e identificadas três categorias de significado: recursos de enfrentamento relativos à finitude; sofrimentos relativos à finitude; sentidos atribuídos à vida e à morte. Percebeu-se como maior sofrimento não a finitude em si, mas o que decorre dela, como perda funcional, preocupação com a família e ameaça de valores. A dificuldade em se falar sobre a morte não necessariamente se encontra em si mesma, mas em identificar o sentido que ela tem para a pessoa e os sofrimentos subjacentes.
\end{abstract}

Palavras-chave: cuidados paliativos, espiritualidade, psicologia, cuidados paliativos na terminalidade da vida.

\section{Introdução}

O fenômeno mundial do envelhecimento populacional encontra-se bem estabelecido por estudos como um de autoria da Organização das Nações Unidas, que demonstra a tendência do aumento contínuo do número de pessoas idosas, em especial em países em desenvolvimento, em decorrência de melhora significativa na nutrição, nas condições sanitárias, na educação e de avanços importantes na medicina, dentre outros fatores (Fundo de População das Nações Unidas \& HelpAge International, 2012). Em contraponto, o aumento na expectativa de vida levou a uma maior prevalência de câncer e de outras doenças crônicas que têm como fator de risco o avanço da idade. Concomitantemente, o desenvolvimento da medicina vem cronificando doenças anteriormente agudas e mortais, promovendo, assim, relativa longevidade a pessoas com essas doenças (Kovács, 2014; Matsumoto, 2012).

Nas últimas décadas, percebe-se a emersão de um cuidado especializado ao sofrimento decorrente dessas doenças crônicas, ameaçadoras da vida e incapacitantes, bem como um resgate à experiência mais natural do processo de morrer, cujo ícone é Dame Cicely Saunders, fundadora do movimento moderno dos cuidados paliativos e da filosofia hospice (Matsumoto, 2012). Conforme guia da Organização Mundial da Saúde (OMS),

Cuidado paliativo é uma abordagem que melhora a qualidade de vida dos pacientes (adultos e crianças) e suas famílias que enfrentam

* Endereço para correspondência: leobhoffmann@yahoo.com problemas associados a doenças que ameaçam a vida. . . Cuidado paliativo é a prevenção e alívio de sofrimento de qualquer natureza - física, psicológica, social ou espiritual - experienciado por adultos e crianças vivendo com problemas de saúde limitadores da vida. (World Health Organization, 2016, p. 5, tradução nossa)

Alguns dos princípios dos cuidados paliativos são: prover alívio de dor e de outros sintomas; afirmar a vida e perceber a morte como processo natural; não procurar adiar nem antecipar a morte; integrar aspectos sociais, psicológicos e espirituais no cuidado ao paciente; oferecer ajuda para que a família consiga enfrentar o processo de adoecimento e o luto porvir (Carvalho, 2018).

Quando a doença é dita terminal, compreende-se que ela evolui com o tempo, ameaça a vida e não tem possibilidade de terapia modificadora de doença com fim curativo. Há critérios de mau prognóstico para as diferentes doenças, conforme delineado por Nicodemo e Torres (2018). Essas enfermidades e seus sintomas implicam sofrimentos em todas as dimensões humanas: física, psicológica, social e espiritual; não somente ao paciente, mas também à sua família. Dessa forma, a prática dos cuidados paliativos é necessariamente interprofissional, a fim de acessar e intervir nos diferentes domínios do sofrimento humano incluindo, portanto, o espiritual.

A espiritualidade é por vezes confundida com religiosidade, porém, em verdade, não se limita nem depende da religião (Best, Butow, \& Olver, 2015; Bovero, Leombruni, Miniotti, Rocca, \& Torta, 2016; Churchill, 2015). A palavra "religião" descende 
da latina religare, que significa "ligar-se" a um absoluto ou essencial; outra etimologia é religere, "reler", na intenção de desvelar a significação de um acontecimento (Hennezel \& Leloup, 1999). Religião pode ser considerada um sistema de crenças e dogmas compartilhados que modelam a conduta, a ser vivenciado de forma espiritual ou não (Safra, 2005), incluindo doutrinas, morais e rituais dentro de uma comunidade (Pessini \& Bertachini, 2011).

Uma das dimensões da vida humana é a espiritual (Carvalho et al., 2012; Churchill, 2015; Hennezel \& Leloup, 1999; Puchalski, Vitillo, Hull, \& Reller, 2014) sendo, desta forma, demanda em potencial de todo paciente, embora seja experiência individual (Best et al., 2015). A espiritualidade diz respeito ao sentido transcendental que uma pessoa atribui à sua vida, aos valores e aos propósitos atrelados a ela (Best et al., 2015; Puchalski \& Romer, 2000; Puchalski et al., 2014). Por "transcendental" se entende aquilo que está além do prático, material e imanente, o que é realizado por um valor pessoal e não por um fim objetivo. O sentido, portanto, volta-se aos elementos que não têm uma representatividade imediata, concreta. Assim, incluem-se aspectos abstratos que fazem parte da vida, como sofrimento, angústia, a própria vida e a morte (Bovero et al., 2016; Churchill, 2015; Fang, Sixsmith, Sinclair, \& Horst, 2016; Pessini \& Bertachini, 2011). Por conseguinte, o sentido é propriamente subjetivo, embora se produza ao longo do tempo em relação com o mundo externo. Segundo Victor Frankl (2016), o sentido da vida difere não somente de pessoa para pessoa, mas de momento para momento, o que torna a terminalidade ocasião especial por possibilitar a descoberta do sentido da vida justamente em seu fim. Porém, na medida em que esses sentidos são questionados ou esvaziados, gera-se sofrimento (Frankl, 2016).

Diversos autores apontaram a importância da espiritualidade na qualidade de vida e no enfrentamento a doenças terminais (Best et al., 2015; Bovero et al., 2016; Broadhurst \& Harrington, 2015; Piderman et al., 2015; Puchalski, King, \& Ferrel., 2018). Promover um espaço adequado de escuta e reflexão à questão da morte e da vida propicia uma elaboração emocional de ressignificação, podendo tornar menos difícil o processo de adoecimento e aproximação da fase final de vida, considerando que esse espaço é negado, muitas vezes, em sociedade, em família e mesmo em ambiente hospitalar. Com a negação, o sofrimento espiritual pode ser compreendido como sofrimento de outra natureza, levando a intervenções inapropriadas (Balducci, 2010). Dessa forma, obter maiores esclarecimentos sobre a forma com que pacientes lidam com o sentido da vida e da morte pode aprimorar os recursos de profissionais da saúde para que acolham e atendam a demandas referentes a essas questões (Proserpio et al., 2016), sendo uma deficiência comum na formação profissional (Best et al., 2015).

\section{Objetivos}

Conhecer os sentidos atribuídos à própria vida $\mathrm{e}$ morte por pacientes com doença em estágio terminal. Os objetivos específicos são:

- Identificar os principais aspectos envolvidos na relação com a ideia da morte;

- Identificar sofrimentos de dimensão psicológica e/ou espiritual relativos à finitude;

- Identificar recursos de enfrentamento de dimensão psicológica e/ou espiritual relativos à finitude.

\section{Método}

Este estudo é de natureza qualitativa e de caráter exploratório, fazendo uso de entrevistas semiestruturadas para a coleta de dados. Segundo Balducci (2010), a melhor forma de investigar sofrimento espiritual e existencial é por meio de estudos qualitativos com questões abertas e análise de conteúdo, pois se trata de um sofrimento que ainda está sendo compreendido e não deve ser avaliado exclusivamente como sofrimento físico, social ou emocional, uma vez que envolve um complexo senso de transcendência, embora estas formas de sofrimento estejam relacionadas.

O estudo foi aprovado por Comitê de Ética em Pesquisa com o número CAAE: 65149717.3.0000.0068. Os colaboradores não foram identificados e foram utilizados nomes fictícios para referência.

\section{Participantes da pesquisa}

Os colaboradores da pesquisa foram idosos em acompanhamento por equipe de cuidados paliativos de um hospital público terciário por pelo menos 3 meses, que tenham sido comunicados sobre o diagnóstico, prognóstico e evolução da doença e que aceitaram participar desta pesquisa. O critério do mínimo de 3 meses de acompanhamento foi estipulado pela organização do hospital no momento da discussão sobre a pesquisa. Em seu entendimento, seria tempo suficiente para que os pacientes tivessem elaborado minimamente a questão do adoecimento, reduzindo, assim, os riscos para sofrimento psicológico advindos das entrevistas.

Os colaboradores foram selecionados dentre pacientes internados na enfermaria de cuidados paliativos do hospital, que conta com nove leitos e equipe especializada. Esta é destinada a pacientes com doença em estágio terminal que demandam controle de sintomas, estão em período de exacerbação da doença ou se encontram em fase final de vida. Dentre outros critérios, a internação nessa enfermaria é realizada mediante discussão e concordância dos familiares e do paciente - quando lúcido e orientado - sobre a limitação de medidas invasivas e de manutenção artificial 
da vida, como uso de drogas vasoativas, reanimação cardiopulmonar, hemodiálise e intubação.

Considerando-se a natureza qualitativa do estudo, que visa explorar a experiência individual, a amostragem foi definida por saturação em pesquisa qualitativa. Conforme explanado por Fontanella et al. (2011), a saturação ocorre quando novas coletas de dados deixam de agregar significativamente na reflexão e aprofundamento do estudo. A saturação pode ser empírica, a partir do momento em que o pesquisador constata ter colhido dados suficientes para responder às questões e, assim, cumprir com o objetivo do trabalho. A saturação também pode ser teórica, quando novas entrevistas não agregam novos temas nem novas categorias de significado no que tange ao escopo da pesquisa (Fontanella et al., 2011; Fontanella, Ricas, \& Turato, 2008). Esta é a saturação que foi visada. Para tanto, a análise foi iniciada durante o período de coleta a fim de identificar a saturação. Não sendo possível verificá-la, o fechamento pode se dar por exaustão, abordando-se todos os participantes elegíveis dentro do tempo reservado para a coleta de dados (Fontanella et al., 2008).

No que tange à seleção dos participantes da pesquisa, os critérios de inclusão foram:

- Estar em acompanhamento por equipe de cuidados paliativos por pelo menos 3 meses;

- Estar com doença avançada em estágio terminal;

- Ter sido informado sobre diagnóstico e prognóstico;

- Apresentar cognição e comunicação preservadas;

- Estar com sintomas controlados no momento da entrevista;

- Ter idade a partir de 60 anos;

- Autorizar utilização do conteúdo da entrevista para fins didáticos, mediante preenchimento do Termo de Consentimento Livre e Esclarecido;

- Participar da entrevista sozinho;

- Estar sendo acompanhado por serviço de psicologia da instância em que se encontra.

Já os critérios de exclusão foram:

- Estar em acompanhamento psicológico com entrevistador;

- Estar em episódio agudo de transtorno mental.

\section{Instrumento de coleta de dados}

Para a coleta de dados foi utilizado um roteiro de entrevista semiestruturada. Este tipo de entrevista permite e incentiva o entrevistado a falar livremente sobre assuntos oriundos do tema principal, a partir de um roteiro de questões que possibilitam esta exploração (Gerhardt \& Silveira, 2009). Não é necessário realizar todas as perguntas, tampouco seguir a ordem em que estão dispostas no roteiro, havendo possibilidade de se incluir questões não previstas ao longo da entrevista, desde que convirjam com os fins da pesquisa. Essa flexibilidade é importante ao se considerar a delicadeza do tema, possibilitando que se adeque o instrumento à resposta emocional de cada entrevistado.

O roteiro contou com duas partes: questionário sociodemográfico e perguntas abertas. O questionário incluiu gênero; idade; diagnóstico principal; naturalidade; escolaridade; estado civil; tempo no estado civil; número de filhos; raça; religião e renda familiar. Já as perguntas abertas baseavam-se em quatro eixos:

a. enfrentamento psicológico/espiritual:

- Ao longo de sua vida o que mais lhe ajudou a passar por momentos e situações difíceis?

- O que mais lhe dá força para enfrentar a situação atual?

- Como você mais gostaria de viver daqui em diante, respeitando as limitações da doença?

b. sofrimento psicológico/espiritual:

- O que você gostaria de ter feito diferente na sua vida?

- O que você faria de diferente se recuperasse sua saúde?

- O que poderia ter sido diferente na sua vida para você falecer em paz?

c. sentido da vida:

- O que você considera que tenha sido o mais importante ao longo da sua vida?

- Com o que você mais se preocupa hoje?

- O que dá sentido e propósito à sua vida?

d. sentido da morte:

- Desde que você soube da doença e do que ela significa, você passou a pensar mais na morte?

- Você já pensava sobre a morte antes do adoecimento?

\section{Procedimento de coleta de dados}

Para a coleta de dados foi realizada, primeiramente, análise de prontuários para seleção dos pacientes que atendiam aos critérios de participação. Em seguida, entrou-se em contato com os pacientes correspondentes a fim de explicar os objetivos da pesquisa e convidá-los a participar. Em caso afirmativo, agendou-se a entrevista e foi assinado o Termo de Consentimento Livre e Esclarecido. Se necessário, as entrevistas poderiam ter continuidade em um segundo momento, de acordo com as condições e disponibilidade do colaborador.

\section{Análise de dados}

Foi realizada análise do discurso, procurando identificar e entender os sentidos manifestados pelos sujeitos, através de diretrizes estabelecidas por Gill (2002). Estas são, em resumo:

- Transcrição literal e detalhada das entrevistas; - Leitura cética e abstraída da busca por uma essência subjacente ao texto, realizando-a de maneira objetiva e sem a pretensão de apreender uma intenção por trás das palavras; 
- Codificação por categorias amplas e inclusivas baseadas no interesse da pesquisa;

- Identificação de padrões e funções do discurso, incluindo nuances e silêncios;

- Análise examinando regularidades e variabilidade nos dados.

\section{Resultados e discussão}

Foram realizadas entrevistas com quatro colaboradores ao longo do período da coleta de dados, aos quais foram atribuídos nomes fictícios. Outras duas entrevistas foram marcadas, porém, no momento agendado, os pacientes estavam com sintomas incapacitantes ou não estavam em condições cognitivas para responder satisfatoriamente às questões, não havendo nova oportunidade. A amostragem foi fechada por exaustão, pois foram entrevistados todos os colaboradores disponíveis no período determinado e não foi possível o fechamento por saturação.

Apresenta-se uma reflexão sobre cada colaborador, a partir de seus dados e temas centrais do discurso. Em seguida, realiza-se a discussão de categorias de significado identificadas no processo da análise de dados. Ao longo do texto, incluem-se trechos de falas dos colaboradores, grifados em itálico, a fim de ilustrar e facilitar as reflexões propostas.

\section{Adriano}

Adriano tem 76 anos de idade e é casado há 34 . Tem quatro filhos, é católico e espírita. Seu diagnóstico principal é de insuficiência cardíaca crônica. O discurso de Adriano é marcado por oscilações entre o polo de significativa autoexigência e cobrança e o polo de menosprezo de si mesmo. Isso pode ser entendido como uma ambivalência, ou seja, existem sentimentos contrários manifestados simultaneamente ou em uma mesma situação (Mesquita \& Duarte, 1996), como se mostra na fala:

"Vamos dizer, sempre se achou um super-homem, ' $a$ h, comigo não acontece isso, estou sempre bem e tal'. E quando acontece, você fala 'eu não sou isso que eu imaginava, sou igual aos outros, ou menos até', não sei”. Os grifos sinalizam os polos referidos. Esta parece ser a maneira pela qual Adriano estabeleceu suas relações: era o chefe de família, responsável financeiramente e pelo bem-estar de todos. Cobrava-se por isso e se julgava fracassado ao se ver incapaz de manter este papel dentro da família com o adoecimento.

Essa dinâmica se manifestou na sua lida com a finitude: diante da impotência causada pela doença, Adriano passou a se ver apenas como um fardo e causador de sofrimento à família, com a sensação de ter perdido sua função como patriarca e provedor. Parece não ter percebido o papel que não lhe pode ser tirado: o de figura de referência e suporte emocional para todos na família.

\section{Bruna}

Bruna tem 74 anos e perdeu o marido há três, com quem teve um casamento de 56 anos e quatro filhos. Ela segue a religião espírita e tem como principal diagnóstico doença pulmonar obstrutiva crônica.

Conforme o discurso de Bruna se desenvolve, ele revela uma mudança na maneira como ela fala de si, apresentando pontos de vista aparentemente antagônicos. Percebe-se que a primeira parte de sua fala é carregada de conceitos que tem de si; conforme seu discurso prossegue, surgem conteúdos opostos a estes conceitos.

Em um primeiro momento: "sempre fui muito de falar, nunca guardei nada, nenhuma mágoa . .., nunca fui pessoa de grandes rancores..., sempre falei, nunca escondi". E em momento posterior: "sempre escondi meus sentimentos. Talvez isso [o casamento ter dado certo] me tirasse um pouco dessa mágoa que eu tenho. É só, não posso falar mais nada".

Bruna pareceu se perceber diferente do que fora ao longo da vida, sendo parte da vivência de uma situação de crise, que convida para uma autorreflexão. Isso pode demonstrar uma mudança importante de atitude perante a vida que, de alguma forma, a própria colaboradora reconhece.

\section{Carmen}

Esta paciente de 60 anos é casada há 38, tem dois filhos e é evangélica. Tem como doença de base uma leucemia mieloide aguda. Carmen foi a única colaboradora que respondeu afirmativamente sobre pensar na morte antes do adoecimento. Conta que teve perdas muito próximas e que conviveu com a morte, de forma que já pensava rotineiramente na própria morte, mesmo quando era hígida. Presenciou a morte inesperada de pessoas jovens, passando a ver o fenômeno como algo que pode acontecer a qualquer momento, não apenas na velhice nem no adoecimento.

De maneira semelhante, ela foi a única que manteve um mesmo recurso de enfrentamento para lidar com dificuldades ao longo da vida e atualmente, na doença: "A fé em Deus. . A mesma fé que eu sempre tive é a que eu tenho hoje". Nesse sentido, Carmen não percebe diante da finitude motivo para alterar sua fé nem sua perspectiva de morte.

Ao longo das falas sobre como lida com a perspectiva de morte, ela afirmou não ficar preocupada "porque não vai adiantar nada". Explica que não adianta ficar ansiosa: "Um dia cada dia né, vivendo cada dia. . . Não adianta querer abreviar nada ..., tem que aguardar". Carmen também foi a única que afirmou já se sentir em paz para falecer, não necessitando de algo para isso. Essas respostas ganham validade na medida em que todo o discurso dela apresenta coerência interna, não havendo elementos indicativos de negação ou contradição.

Não se pode deduzir que sua aceitação da morte decorra de conviver com essa ideia e naturalizá-la ao longo 
da vida, embora isso seja possível. Serve de contraexemplo, porém, para a crença usual de que falar ou pensar sobre morte fora desse contexto compromete o enfrentamento.

\section{Denise}

A paciente Denise tem 67 anos de idade, é viúva há dez e tem sete filhos. É evangélica e possui como principal diagnóstico neoplasia gástrica. Ela foi a única colaboradora que respondeu negativamente à pergunta sobre pensar mais na morte após o adoecimento: "Não penso em morte, não. $O$ dia que for para ir eu vou, se for para melhorar eu melhoro".

Isso não significa, porém, que ela esteja em processo de negação. Afinal, Denise demonstra reconhecer a terminalidade em falas como: "O dia que for para ir eu vou. Se [Deus] quiser me levar me leva. O mais importante na minha vida era ter minha saúde, se não tenho saúde não tenho nada".

Ela coloca sua saúde no passado e afirma que isso era o mais importante para ela, logo, hoje reconhece sua debilidade e alguma perda do que lhe dava sentido para viver. Demonstra, portanto, atitude de resignação, compreendida como submissão e passividade diante de um destino não desejado e inevitável.

Denise tampouco pensava sobre a morte antes do adoecimento: "Eu não, eu penso em viver!". A linguagem não verbal, nesse caso, indicou uma surpresa com a pergunta, como se questionasse "por que alguém pensaria na morte sem estar doente?", talvez com uma crença de que pensar na morte é contrário à vida. De fato, ao relacionar saúde à capacidade resolutiva, valor importante para ela, pensar na morte é pensar em doença, e pensar em doença é ir contra esses valores.

\section{Categorias de significado}

Discorre-se inicialmente sobre os principais recursos de enfrentamento relativos à finitude: recursos internos e fé religiosa.

A categoria seguinte trata dos sofrimentos relativos à finitude, em especial a dependência e senso de responsabilidade, o medo do pós-morte e o sofrimento social, demonstrando como o sofrimento nesse contexto pode ser mais originário de questões secundárias do que da terminalidade propriamente dita.

Por fim, são discutidos os sentidos percebidos em relação à vida e à morte: autorrealização, família e aceitação da morte.

\section{Recursos de enfrentamento relativos à finitude - recursos internos}

Alguns destes recursos foram identificados em três participantes, manifestando-se através de referências como resolutividade, autonomia, iniciativa, coragem, atividade (em oposição à passividade), capacidade de ressignificação e de rever valores: "A força de vontade e determinação. Isso acho que é o mínimo indispensável para você conseguir as coisas" (Adriano); "Agora que eu tenho só esse pouquinho eu dou um valor danado para ela [vida], pequenas coisas me dão alegria, pequenas alegrias me fazem feliz" (Bruna).

Alguns estudos mostram o valor que pacientes dão à independência e autonomia para sua qualidade de vida (Melin-Johansson, Ödling, Axelsson, \& Danielson, 2008). Nesse sentido, preservar a posição de autonomia e responsabilidade pelas próprias decisões mostra-se boa estratégia de enfrentamento tanto dos pacientes quanto da equipe e da família para com os pacientes.

\section{Recursos de enfrentamento relativos à finitude - fé religiosa}

A fé religiosa aparece em menor ou maior medida em três colaboradores, excetuando-se Denise, que não evoca a religiosidade como meio de enfrentamento. Bruna fala claramente sobre como sua religiosidade a ajuda, encontrando paz na certeza de que viverá novamente e com oportunidades novas, dentre outros elementos positivos: "Conheci o espiritismo e fiquei, ... acho que é com essa que eu vou. .., vou partir com essa . ., me sinto muito bem, fiquei bem mais humana, .. . mais calma" (Bruna).

A fé religiosa é um recurso de enfrentamento próprio da dimensão espiritual, junto a crenças e valores espirituais (Puchalski \& Romer, 2000), além da esperança (Broadhurst \& Harrington, 2015). Tais recursos são distinguidos dos psicológicos, como boa capacidade de elaboração emocional e de autopercepção, postura ativa diante do processo de adoecimento e disponibilização de mecanismos de defesa funcionais.

Além disso, a fé volta-se para o desconhecido e permite um vínculo com este, ou seja, com o transcendente (Safra, 2013), facilitando a aproximação com este fenômeno inexplicável que é a morte.

\section{Sofrimentos relativos à finitude - dependência e senso de responsabilidade}

A perda da autonomia e independência, as limitações impostas pelas doenças e o sentimento de impotência fazem parte de uma espécie de sofrimento destacada por três dos quatro colaboradores. Isso aparece na medida em que estes passaram a depender de terceiros para os autocuidados: "Eu nunca fui dependente, sempre os outros dependeram de mim, e até que haja essa inversão é, sei lá, doído, é sofrido" (Adriano).

Esses mesmos três participantes expressaram enfaticamente, também, o sofrimento pela preocupação do bem-estar dos seus entes queridos após sua partida, no sentido de se responsabilizar pela felicidade dos familiares e, no caso, lhes causar tristeza ao morrer: "Eles [os dois filhos que moram com a colaboradora] são muito grudados em mim... Tenho dois [filhos] que tenho 
maior tristeza de morrer e deixar eles" (Denise); “O que eu mais me preocupo é essa falta que eu vou fazer para os familiares, os amigos etc. . A preocupação de não deixar a família, vamos dizer, em mal estado"(Adriano), referindo-se à situação da família após seu falecimento.

Carmen não expressou essa forma de sofrimento, porque não identificou ninguém dependendo dela, afirmando estar tranquila justamente por não ter dependentes: "Eu me vejo assim, como se não tivesse . . motivo pra preocupações... Tenho os filhos, todo mundo trabalha, todo mundo faz suas coisas, [tem] seus maridos, os netos, então assim, eu não tenho quem dependa de mim; na realidade, eu só que estou dependendo dos outros" (Carmen).

Considerando-se este papel da responsabilidade por outros como um sentido para viver, a partir do momento em que se perde a capacidade de desempenhá-lo, perde-se também esse sentido, o que leva ao sofrimento (Frankl, 2016).

Além disso, percebe-se que todos os que sofrem com a impotência trazida pela doença e com a dependência de terceiros sofrem também com os familiares supostamente dependendo deles, em uma relação necessariamente recíproca. Em outras palavras, responsabilizar-se por causar sofrimento ao outro devido à própria morte esteve relacionado com o sofrimento por depender deste para seus cuidados. Essa reflexão revela uma diferença não dita de natureza hierárquica nas responsabilidades e papeis na entidade familiar. Desvela-se um caráter vertical em uma relação em que é sofrido depender de outros para o próprio bem-estar, ao mesmo tempo em que é esperado que estes sejam dependentes para a felicidade.

\section{Sofrimentos relativos à finitude - medo do pós-morte}

Esta forma de sofrimento foi expressa por Bruna, sendo relativa ao medo de como seria o pós-morte, devido a uma crença na possibilidade da manutenção da consciência, enclausurada na cova junto ao corpo físico - razão pela qual desejava ser cremada:

A única coisa que eu tenho medo, no caso ...., eu tenho medo da cova. Daquele buraco. Eu queria ser cremada. ... Medo de ficar sem ar lá. Mas acho que isso é uma tolice, uma criancice, né? . . Eu ouço falar tantos casos, tanta, eu leio tanto livro espirita, tanta história que eles dizem que é verdadeira, que as pessoas ficam se debatendo, mas precisa ser muito mau para ficar numa situação dessas. Acho que não vou chegar num ponto desse, eu não sou má.

Em primeiro momento, poderia se pensar que Bruna se refere à cova propriamente dita ou à possibilidade de acordar nela sem ter morrido de fato. Quando ela cita o espiritismo ("eu leio tanto livro espírita") e o caráter moral ("precisa ser muito mau para ficar numa situação dessas"), fica claro que este medo é de escopo religioso. Estudiosos da religiosidade e da espiritualidade reconhecem que há copings negativos e crenças religiosas que não cumprem função adaptativa e geram estresse (Koenig, 2012; Panzini \& Bandeira, 2007); de forma que a paciente poderia se beneficiar da assistência desta natureza. Entretanto, percebe-se que para Bruna a relação com a religião cumpre propósito mais benéfico do que prejudicial no seu enfrentamento, como ocorre no coping religioso/espiritual em geral (Panzini \& Bandeira, 2007).

Ademais, conforme a colaboradora se questiona sobre a relevância disso ("tolice, criancice"), corre-se o risco de que este sofrimento seja subestimado pela equipe e manifestado de outra forma, tornando o tratamento como um todo mais complexo e menos eficaz, tal como elucidado por Balducci (2010). Afinal, como apontaram Best et al. (2015), os pacientes em geral falam de seus valores e preocupações espirituais somente a partir do convite do médico, e não espontaneamente. Ao mesmo tempo, médicos que incorporaram avaliação espiritual a suas clínicas relatam maior nível de intimidade na relação médico-paciente, melhorando a compreensão sobre quem está sendo atendido e aprofundando a atenção à saúde (Puchalski \& Romer, 2000).

\section{Sofrimentos relativos à finitude - sofrimento social}

Em um momento de sua fala, Bruna traz a questão do emagrecimento: "Nossa, eu pesava 62 quilos, depois fui emagrecendo com a doença, passei a ter 52. Mesmo assim, eu devo ter perdido de 8 a 10 quilos, é muito, muito".

Ao longo da prática clínica, é comum perceber pacientes preocupados com o emagrecimento por associarem-no com adoecimento e morte. Entretanto, conforme a fala de Bruna prossegue, desvela-se a real preocupação da participante com o emagrecimento:

Nem sei o que eu faço para engordar porque eu, às vezes, tenho vontade de sair no meu portão, a gente mora numa rua gostosa, ficar ali um pouquinho, olhando, e não tenho coragem, estou me achando tão magra, e o povo fica pensando que eu estou com câncer, estou muito magra, olha meus braços. . . Quero ver se eu engordo um pouco, fica chato, né. A primeira coisa que o povo pensa é 'está com câncer' com essa magreza.

Além dos sofrimentos próprios da debilidade física e da terminalidade, reconhece-se nessa fala um sofrimento social na medida em que Bruna se identifica com um estereótipo socialmente carregado de piedade e valores negativos. Conforme explanado por Werlang \& Mendes (2013), o sofrimento social está presente a partir de sentimentos de perda, humilhação e isolamento social, advindo da perda de um objeto social que permitia o vínculo e a interação com demais membros do grupo social. Nesse momento, portanto, a representação social do câncer pode angustiar Bruna tanto quanto o significado biológico do emagrecimento: o avanço de uma doença grave e incurável. 


\section{Sentidos atribuídos à vida e à morte - autorrealização}

Da mesma forma que os recursos internos de enfrentamento, um dos sentidos predominantes relativos à própria vida é interno e diz respeito ao sentimento de autorrealização. Pode-se entender esse sentimento em termos de autonomia, realização pessoal, sensação de trabalho cumprido e de ter sido bem-sucedido na vida. Esse sentido esteve presente em três dos colaboradores.

Adriano afirma: "o mais importante? Foi ter conseguido as metas que uma pessoa gostaria de atingir. Em relação a parte financeira, em relação a família, esse tipo de coisa".

Denise destaca o valor não da saúde propriamente dita, mas do que se é possível conquistar com ela: "o mais importante na minha vida era ter minha saúde, se não tenho saúde não tenho nada.... Com saúde se faz tudo, vence tudo, vai em todo lugar, resolve tudo".

Já Carmen expressa um sentido de satisfação com a própria vida: "eu nunca deixei passar as oportunidades, fiz tudo que deu para fazer".

\section{Sentidos atribuídos à vida e à morte - família}

A família apareceu como um elemento importante no discurso de todos os colaboradores. Três destes responderam que ela provê a vida de sentido e propósito:

Faz mais sentido é ter essa união de família... $O$ sentido ai de haver uma, tem que haver uma união, uma coisa assim, para te dar esse ânimo, ou coisa parecida ... Quero sarar para poder continuar convivendo com o pessoal, de uma maneira mais tranquila, mais suave (Adriano)

É o que eu digo, é minha casa, minha familia, ver minha família melhorar de vida, ver eles com saúde, família, genros, ver minhas filhas prosperar com o marido e ver elas bem com o marido. O mais importante para mim foi meus filhos, não tenho dúvida (Bruna)

Sentido? Ah, continuar vivendo junto com minha familia até a hora que for a hora final. Ter minha família por perto (Carmen)

O sentimento de estar em meio à família e ser cuidado por pessoas íntimas e próximas, como os familiares, tende a promover independência e bem-estar, melhorando a qualidade de vida mesmo na condição de terminalidade (Melin-Johansson et al., 2008).

Indagada sobre o que teria de ter acontecido na sua vida para que falecesse em paz, Denise responde: "Cuidar dos meus filhos. Dar um bom estudo para eles, dar boas coisas para eles. . Todos eles deveriam ter estudo bom. . . Eu tenho sete filhos, só que tenho dois que tenho maior tristeza de morrer e deixar eles". Nesse caso, a família promove preocupação e sentimento de pendência e não necessariamente atua como provedora de sentido à vida.

\section{Sentidos atribuídos à vida e à morte - aceitação da morte}

Compreende-se aceitação como postura tranquila e ativa perante a morte, havendo uma disponibilidade interna de se aproximar dela; nesse sentido, diferindo-se de apatia, repulsa e passividade (Kübler-Ross, 1996). Assim, a aceitação foi perceptível em dois colaboradores, que expressaram sentimento de plenitude na vida que tiveram e sentindo-se em paz para falecer.

Teve um tempo em que eu andei meio 'apavoradinha', mas eu falei, é por aí, não sou a única, o presidente vai, a princesa vai, o rei vai, a artista vai, e por que eu não? Eu tenho que ir e acabou... Não vou dizer para você que estou prontinha para ir, claro que não, mas estou procurando. (Bruna)

Carmen, quando questionada sobre o que lhe faltava para poder falecer em paz, afirmou "me sinto em paz" e manteve todo seu discurso coerente com esta afirmação, como foi possível verificar na análise do seu discurso.

Diferentemente, Adriano demonstrou sensação de que a morte encurtou o que planejara para sua vida, afirmando que "não deu tempo". Fez analogia a um período de férias ou aposentadoria em que poderia fazer o que bem entendesse sem se preocupar com dinheiro ou tempo, só que este período não veio.

Encontrar um sentido para a vida, qualquer que seja, promove melhor aceitação e adaptação ao contexto de terminalidade. Um estudo feito com 253 pacientes com câncer avançado propôs-se a avaliar duas formas de psicoterapia em grupo: centrada no sentido e terapia de apoio. Breitbart et al. (2015) descobriram no primeiro grupo uma diferença significativa na melhora de questões espirituais, psicológicas e existenciais. Embora a pesquisa se referisse a pacientes oncológicos, a questão do sentido tende a emergir diante de uma doença terminal nas várias formas que esta possa assumir. Portanto, na mesma linha, investigando o desejo de morte em pessoas diagnosticadas com esclerose lateral amiotrófica, um estudo indiano propõe que perceber um sentido nesse contexto promove melhor enfrentamento e aceitação da perspectiva de morte (Gourie-Devi, Gupta, Sharma, Pardasani, \& Maheshwari, 2017).

Assim, os sentidos identificados neste estudo contribuíram na amenização do sofrimento e no enfrentamento da situação, uma vez que enaltecem questões significativas e positivas, ao invés de sofrimento e angústia.

\section{Considerações finais}

$\mathrm{O}$ adoecimento e a morte sempre fizeram parte da humanidade e foram fontes de sofrimento. Este estudo 
contribuiu na elucidação sobre o sentido da vida e da morte, que se refere a um sofrimento de natureza existencial e espiritual, dentre outros elementos relativos a este tema.

Como limitação encontrada nesta pesquisa, aponta-se a dificuldade em encontrar pacientes elegíveis para as entrevistas. $\mathrm{O}$ critério de estar sendo acompanhado por equipe de cuidados paliativos por um mínimo de três meses foi o principal impeditivo para a elegibilidade. Ele foi pensado para preservar pacientes com diagnóstico recente de terminalidade e, nesse sentido, cumpriu seu propósito. Todavia, é possível que alguns pacientes com menos de três meses de acompanhamento em cuidados paliativos estivessem em condições clínicas e emocionais de participar da pesquisa. Além disso, definir o número de participantes conforme a disponibilidade no período de coleta de dados parece mais coerente do que almejar a saturação em pesquisa qualitativa, considerando-se a profundidade e incipiência do tema. Esses aspectos poderiam ser repensados, portanto, em um futuro estudo dessa natureza.

Foi possível perceber que, na condição de paciente com doença terminal e em contato com a própria finitude, os principais recursos de enfrentamento foram internos, no sentido de valorização da vida que foi vivida e das conquistas alcançadas, além da fé religiosa em menor ou maior grau.

As maiores causas de sofrimento relatadas pelos colaboradores foram medo da condição após a morte, sofrimento pelo estigma social de pessoa doente e as limitações impostas pela doença - perda de autonomia e de independência e sentimento de impotência - aliadas à preocupação com o bem-estar da família como cuidadora e futura enlutada.

Nesse sentido, considera-se importante a relação identificada entre o sofrimento de depender de terceiros e a crença de que estes dependem do paciente, tratando-se de um sofrimento duplo. Isso parece estar atrelado a uma forte valorização de qualidades intrínsecas, a saber, as capacidades de resolutividade, realização e postura ativa. Dessa forma, diante da impotência característica do adoecimento, o duplo sofrimento aparece na dependência dos outros e no sentimento de lhes causar sofrimento.

Os principais sentidos atribuídos à vida e à morte foram identificados como autorrealização, que promove sentimentos de plenitude e satisfação com a própria vida; família, tida como propósito e motivação para se continuar vivendo, e uma aceitação da morte com naturalidade.

De alguma forma, o sentido aponta para uma relação, seja com um valor, com uma crença ou com pessoas. É uma relação direta quando um paciente afirma que a família é o mais importante para ele ou quando diz que deseja ver os filhos e netos crescerem; é direta, também, quando recorre a Deus como provedor de forças e esperança para lidar com situações difíceis. Além disso, uma relação indireta aparece quando os pacientes valorizam sua independência, afinal, os colaboradores desejavam ser funcionais e resolutivos para prover e cuidar dos demais e não lhes causar sofrimento ao depender de seus cuidados nem lhes causar a dor do luto com sua morte.

Em suma, o cerne do sofrimento espiritual não foi identificado como a finitude em si, mas sim com o que decorre dela - o que é próprio de cada indivíduo devido ao processo de subjetivação do que a morte representa e do que vem atrelado a ela. Falar sobre morte não faz emergir, necessariamente, sofrimento, pois este se encontra na preocupação pelos familiares, na perda da funcionalidade e em qualquer valor que esteja comprometido pelo adoecimento e pelos limites da finitude. Por ser tão sutil e pessoal, é que se mostra ainda mais importante a atenção espiritual a pacientes em cuidados paliativos, para que estas questões existenciais tenham voz e façam parte do cuidado como um todo. A dificuldade em se falar sobre a morte não necessariamente se encontra em si mesma, mas sim em identificar o sentido que ela tem para a pessoa e os sofrimentos subjacentes.

\section{Meanings of life and death: reflections of patients in palliative care}

Abstract: Palliative care proposes to look after the suffering of patients with chronic and life-threatening diseases in the four dimensions: physical, social, psychological, spiritual. This latter refers to imbuing meaning to transcendent aspects, such as life and death. This study seeks to know these meanings. It is a qualitative and exploratory research, using semi-structured interviews to data collection and discourse analysis to data analysis. Four patients were interviewed and three meaning categories were identified: coping mechanisms related to finitude, sufferings related to finitude and meanings attributed to life and death. It was clear that the core of suffering is not terminality itself, but what comes of it, such as functional loss, worrying about the family and value threatening. The difficulty in talking about death is not necessarily found in death itself, but in identifying the meaning it has to the person and the sufferings underneath.

Keywords: palliative care, spirituality, psychology, hospice care.

\section{Sentidos de vida y muerte: reflexiones de pacientes en cuidados paliativos}

Resumen: Los cuidados paliativos se proponen mitigar el sufrimiento de pacientes con enfermedades crónicas y amenazadoras de vida en cuatro dimensiones: física, social, psicológica y espiritual. En la dimensión espiritural se pretende llenar de sentido 
con aspectos trascendentales, como vida y muerte. Este estudio tiene como objetivo conocer estos sentidos. Para ello, se utilizó el método cualitativo de carácter exploratorio y aplicó entrevistas semiestructuradas para recopilar los datos y el análisis del discurso. Se entrevistaron a cuatro pacientes, y se identificó tres categorías de significado: recursos de afrontamiento relacionados con la finitud, sufrimientos relacionados con la finitud y sentidos atribuidos a la vida y la muerte. Se observó que el mayor sufrimiento no era la finitud en sí, sino lo que deriva de ella, como la pérdida funcional, la preocupación por la familia y la amenza de valores. La dificultad de hablar acerca de la muerte no reside necesariamente en sí misma, sino en identificar el sentido que tiene para la persona y los sufrimientos subyacentes.

Palabras clave: cuidados paliativos, espiritualidad, psicología, cuidados paliativos al final de la vida.

\section{Sens de la vie et de la mort: réflexions de patients en soins palliatifs}

Résumé: Les soins palliatifs visent à soulanger les souffrances des patients atteints de maladies chroniques et potentiellement mortelles dans quatre domaines: physique, social, psychologique et spirituel. Ce dernier renvoie au sens que l'on peut donner à des aspects transcendants tels que la vie et la mort. Explorer ces différentes facettes est l'objective de cette étude. II s'agit d'une recherche qualitative de nature exploratoire, menée à partir d'entretiens semi-directifs pour la collecte de données et l'analyse du discours. Quatre patients ont été interrogés et trois catégories de signification ont été identifiées: les ressources d'adaptation liées à la finitude, la souffrance associées à la finitude, et les sens attribué à la vie et à la mort. Il en ressort que la plus grande souffrance n'est pas l'idée de finitude en soi, mais ce qui en découle, comme la perte d'autonomie fonctionnelle, l'anxiété à l'égard de la famille et la remise en question des valeurs. La difficulté de parler de la mort ne réside cependant pas nécessairement dans le fait de parler de la mort elle-même, mais dans l'identification du sens qu'elle revêt pour la personne concernée et dans l'identification des souffrances sous-jacentes.

Mots-clés: soins palliatifs, spiritualité, psychologie, soins palliatifs en fin de vie.

\section{Referências}

Balducci, L. (2010). Beyond quality of life: the meaning of death and suffering in palliative care. Asian Pacific Journal of Cancer Prevention, 11(1), 41-44. Recuperado de https://bit.ly/3vvwF4k

Best, M., Butow, P., \& Olver, I. (2016). Doctors discussing religion and spirituality: a systematic literature review. Palliative Medicine, 30(4), 327-337. doi: $10.1177 / 0269216315600912$

Bovero, A., Leombruni, P., Miniotti, M., Rocca, G., \& Torta, R. (2016). Spirituality, quality of life, psychological adjustment in terminal cancer patients in hospice. European Journal of Cancer Care, 25(6), 961-969. doi: 10.1111/ecc.12360

Breitbart, W., Rosenfeld, B., Pessin, H., Applebaum, A., Kulikowski, J., \& Lichtenthal, W. G. (2015). Meaningcentered group psychotherapy: an effective intervention for improving psychological well-being in patients with advanced cancer. Journal of clinical oncology, 33(7), 749-754. doi: 10.1200/JCO.2014.57.2198

Broadhurst, K., \& Harrington, A. (2016). A mixed method thematic review: the importance of hope to the dying patient. Journal of Advanced Nursing, 72(1), 18-32. doi: $10.1111 /$ jan. 12765

Carvalho, G. D. A., Acioly, C. M. C., Lima, O. B. A., Melo, V. C. et al. (2012). Abordando a espiritualidade de indivíduos em cuidados paliativos: investigação em periódicos online. In $15^{\circ}$ Congresso Brasileiro dos Conselhos de Enfermagem (pp. 1-7). Fortaleza, CE: Cofen. Recuperado de http:// docplayer.com.br/16915468-Abordando-a-espiritualidade- de-individuos-em-cuidados-paliativos-investigacao-emperiodicos-online-1.html

Carvalho, R. T. (2018). Cuidados paliativos: conceitos e princípios. In R. T. Carvalho, M. R. B. Souza, E. M. Franck, R. T. V. Polastrini, D. Crispim, S. M. C. Jales, S. M. M. Barbosa, \& S. H. B. Torres (Eds.), Manual da residência de cuidados paliativos: Abordagem multidisciplinar (pp. 2-10). Barueri, SP: Manole.

Churchill, L. R. (2015). Embracing a broad spirituality in end of life discussions and advanced care planning. Journal of Religion and Health, 54(2), 759-764. doi: 10.1007/ s10943-014-9988-y

Fang, M. L., Sixsmith, J., Sinclair, S., \& Horst, G. (2016). A knowledge synthesis of culturally - and spiritually sensitive end-of-life care: Findings from a scoping review. BMC Geriatrics, 16, 1-14. doi: 10.1186/s12877-016-0282-6

Fontanella, B. J. B., Luchesi, B. M., Saidel, M. G. B., Ricas, J., Turato, E. R., \& Melo, D. G. (2011). Amostragem em pesquisas qualitativas: Proposta de procedimentos para constatar saturação teórica. Caderno de Saúde Pública, 27(2), 389-394. Recuperado de https://bit.ly/3tm8Qdn

Fontanella, B. J. B., Ricas, J., \& Turato, E. R. (2008). Amostragem por saturação em pesquisas qualitativas em saúde: contribuições teóricas. Caderno de Saúde Pública, 24(1), 17-27. Recuperado de https://bit.ly/2P0njwH

Frankl, V. E. (2016). Em busca de sentido. São Paulo, SP: Vozes. Fundo de População das Nações Unidas \& HelpAge International. (2012). Envelhecimento no século XXI: 
Celebração e desafio. Nova York: UNFPA. Recuperado de https://bit.ly/2Nltefr

Gerhardt, T. E., \& Silveira, D. T. (Orgs.). (2009). Métodos de pesquisa. Porto Alegre, RS: Editora da UFRGS.

Gill, R. (2002). Análise do discurso. In M. W. Bauer \& G. Gaskell (Eds.), Pesquisa qualitativa com texto imagem e som: um manual prático (pp. 244-269). Petrópolis, RJ: Vozes.

Gourie-Devi, M, Gupta, R., Sharma, V., Pardasani, V., \& Maheshwari, S. (2017). An insight into death wish among patients with amyotrophic lateral sclerosis in India using "wish-to-die questionnaire". Neurology India, 65(1), 46-51. doi: 10.4103/0028-3886.198177

Hennezel, M., \& Leloup, J-Y. (1999). A arte de morrer. Petrópolis, RJ: Vozes.

Koenig, H. G. (2012). Espiritualidade no cuidado com o paciente: por quê, como, quando e o quê. São Paulo, SP: FE Editora.

Kovács, M. J. (2014). A caminho da morte com dignidade no século XXI. Revista Bioética, 22(1), 94-104. Recuperado de https://bit.ly/3qNTkpe

Kübler-Ross, E. (1996). Sobre a morte e o morrer. São Paulo, SP: Martins Fontes.

Matsumoto, D. Y. (2012). Cuidados paliativos: conceito, fundamentos e princípios. In R. T. Carvalho, \& H. A. Parsons (Orgs.), Manual de cuidados paliativos ANCP (pp. 23-30). São Paulo, SP: ANCP.

Melin-Johansson, C., Ödling, G., Axelsson, B., \& Danielson, E. (2008). The meaning of quality of life: Narrations by patients with incurable cancer in palliative home care. Palliative and Supportive Care, 6, 231-238. doi: $10.1017 / \mathrm{S} 1478951508000370$

Mesquita, R., \& Duarte, F. (1996). Dicionário de psicologia. Lisboa: Plátano.

Nicodemo, I. P., \& Torres, S. H. B. (2018). Indicações de Cuidado Paliativo: os cuidados paliativos recomendados para cada paciente. In R. T. Carvalho et al. (Eds.), Manual da Residência de Cuidados Paliativos: abordagem multidisciplinar (pp. 21-36). São Paulo, SP: Editora Manole.

Panzini, R. G., \& Bandeira, D. R. (2007). Coping (enfrentamento) religioso/espiritual. Revista de Psiquiatria Clínica, 34(1), 126-135. doi: 10.1590/ S0101-60832007000700016
Pessini, L., \& Bertachini, L. (2011). Espiritualidade e cuidados paliativos. In R. D. Moritz (Org.). Conflitos bioéticos do viver e do morrer. Brasília, DF: Conselho Federal de Medicina.

Piderman, K., Kung, S., Jenkins, S. M., Euerle, T. T., Yoder, T. J., Kwete, G. M., \& Lapid, M. I. (2015). Respecting the spiritual side of advanced cancer care: a systematic review. Current Oncology Reports, 17(2), 1-9. doi: 10.1007/s11912-014-0429-6

Proserpio, T., Veneroni, L., Silva, M., Lassaletta, A., Lorenzo, R., Magni, C., . . F Ferrari, A. (2016). Spiritual support for adolescent cancer patients: a survey of pediatric oncology centers in Italy and Spain. Tumori, 102(4), 376-380. doi: 10.5301/tj.5000494

Puchalski, C., \& Romer, A. L. (2000). Taking a spiritual history allows clinicians to understand patients more fully. Journal of Palliative Medicine, 3(1), 129-137. doi: 10.1089/jpm.2000.3.129

Puchalski, C. M., Vitillo, R., Hull, S. K., \& Reller, N. (2014). Improving the spiritual dimension of whole person care: Reaching national and international consensus. Journal of Palliative Medicine, 17(6), 642-656. doi: 10.1089/ jpm.2014.9427

Puchalski, C. M., King, S. D. W., \& Ferrell, B. R. (2018). Spiritual considerations. Hematology/Oncology Clinics of North America, 32(3), 505-517. doi: 10.1016/j.hoc.2018.01.011.

Safra, G. (2005). Espiritualidade e religiosidade na clínica contemporânea. In M. M. Amatuzzi (Org.), Psicologia e espiritualidade (pp. 205-212). São Paulo, SP: Paulus.

Safra, G. (2013). Disponibilidades para a realidade psíquica não sensorial: Fé, esperança e caritas. Ide (São Paulo), 36(56), 91-104. Recuperado de https://bit.ly/3ePwStc

Werlang, R., \& Mendes, J. M. R. (2013). Sofrimento social. Serviço Social \& Sociedade, (116), 743-768. doi: 10.1590/S0101-66282013000400009

World Health Organization. (2016). Planning and implementing palliative care services: A guide for programme managers. Geneva: WHO.

Recebido: $5 / 3 / 2018$

Revisado: 29/6/2020

Aprovado: 8/3/2021 